\title{
Measuring the Ethical Levels of Special Education Teachers
}

\author{
Craig J. Rice ${ }^{1, *}$ and Carl Stein ${ }^{2}$ \\ ${ }^{I}$ Department of Elementary and Special Education, Middle Tennessee State University; ${ }^{2}$ Department of Education, \\ Heidelberg College
}

\begin{abstract}
Dialogue discussing the moral role of the teacher appears in the educational literature with greater and greater frequency each year. Fenstermachers [1] states, "The teacher's conduct, at all times and in all ways, is a moral matter. For that reason alone, teaching is a profoundly moral activity (p. 133)". This statement reflects the strong sentiments being expressed in the education literature. This is the first study to examine the moral reasoning ability of special education teachers [2]. The primary finding of this research is that special education teachers have a significantly lower level of moral reasoning than the norms established for all other reported professions. The results were consistent with previous findings reporting that teachers in general have lower levels of moral reasoning ability as measured by the DIT P-Score of the Defining Issues Test than other professionals.
\end{abstract}

\section{INTRODUCTION}

Over the last decade, the centuries old idea that an educator is a "moral agent" charged with a "uniquely moral task" has experienced a significant rebirth in the educational literature [3-15]. For example, Althof and Oser [16] write "At last, the moral dimensions of schooling have been rediscovered as a major arena of both educational philosophy and research and of practice in the teaching profession (p. 253)". Sockett [17] states that all teaching efforts depend on "three interlinked conditions for success: (1) the development of trust, (2) the establishment of a partnership between the public and professionals to dissolve the tension of competition for control, and (3) the teacher's role as a moral agent (p. 224)". The rebirth of a substantial discourse avowing the moral basis of teaching includes several educational writers who make the important statement that the craft of teaching is among the most morally demanding of all professions $[18,19]$. The current renaissance of a significant discourse about the moral basis of teaching differs from previous eras in a number of significant ways.

The prior history of research and writing regarding moral aspects of teaching was generally (a) grounded in values oriented approaches, (b) centered at the institutional level of schooling, and (c) supported with little empirical research [20]. In contrast, the current moral dialogue (a) relies on a cognitive developmental view of morality, (b) is focused on the abilities of the individual, and (c) is supported by objective empirically based research.

\section{TEACHERS AND MORAL REASONING}

The research on teacher's moral reasoning level has yielded a consistent pattern of findings regarding the moral reasoning abilities of educational practitioners. The specific issue that has created the most curiosity over the past several years is the consistent finding that a teacher's ability to

*Address correspondence to this author at the Middle Tennessee State University, Murfreesboro, TN 37132-0001, USA; Email: crice@mtsu.edu engage in moral reasoning is markedly lower than that of other professionals [7, 21-24]. Additionally unsettling to some educational researchers are studies illustrating a teacher's moral reasoning ability is consistently below that of other college majors and below adults in general [7, 25].

The mean principled moral reasoning score or DIT PScore, reported for teachers in thirty research studies over the last 15 years has been consistently below the average established for adults in general. The range of principled moral reasoning scores reported in these studies is between 28.5 to the low 40s [7, 25-28]. The most recent reported mean principled moral reasoning score, DIT P-Score, for teachers in general is 39.5 [7]. This places the mean level of moral reasoning for teachers below the norms established for all other measured professions, and groups such as navy enlisted men, accountants, law students, business students, staff nurses, dental students and medical students.

Given the widely acknowledged lofty demands of teaching, many researchers think colleges are failing to prepare teachers with the moral attributes required to undertake the complex task of teaching [24, 29, 30]. Reiman [31] found that pre-service teachers enter college with a DIT-P score in the mid 30s and graduate with an average gain in moral reasoning of 12 points.

Does moral reasoning effect a teachers behavior? A reasonable conclusion is that a consistent positive relationship exists between the way one thinks and the way one behaves. The rationale being, people with higher levels of moral reasoning tend to be those who act in more mature and more socially desirable fashions [32-34].

Schlaefi, Rest, \& Thoma [35] reviewed all of the published research that linked a score on the Defining Issues Test with a behavioral outcome, and they reported that there appears to be a strong link between moral reasoning level and behavior. Following a comprehensive review of 75 studies that examined the link between moral reasoning and moral behavior, Blasi [36] noted that a considerable majority of the studies demonstrated a significant link between moral 
reasoning and moral behavior in both children and adults. He cautions, however, that moral reasoning is an extremely complex phenomena; consequently, interpreting links with behavioral outcomes always needs to be done with great caution. He concludes, "In sum, moral reasoning stages are clearly related to behavioral independence in judgment but less clearly and only under certain circumstances to independence in moral action (p. 37)". Duckett and Ryden [37] reported that when age, GPA, ACT scores, achievement scores, prior course credits and a DIT P-Score were entered into a stepwise multiple linear regression to the score of the Clinical Evaluation Tool which is used to rate clinical nursing performance, "the DIT P Score which entered at Step 1, accounted for $34 \%$ of the variance, age which entered at step two, accounted for an additional $12 \%$, the rest of the variables did not enter. Tippins, Tobin and Hook [38] report that it is because of requirement of action that teaching is a moral enterprise, "Teachers experience contradictions and moral struggles because the very nature of acting requires choices involving moral decisions (p. 222)".

\section{SPECIAL EDUCATION TEACHERS AND MORAL REASONING}

Many researchers agree that the special educator is challenged to make a variety of consequential decisions that generally go beyond the obligations of the regular educator [39]. While there is virtually universal agreement that the mission of special education includes a moral element, little agreement can be found following that initial agreement. It may be that special educators of high moral reasoning ability are attracted to special education, thus the requirement of moral practitioners is satisfied. It is also possible that special education, like general education, lacks teachers with high moral reasoning ability. Another possibility is that the moral task at hand in special education has the effect of raising the level of moral reasoning of special educators as they function in the position. Yet other educational researchers believe that preparing teachers, including special educators, with the attributes required to adequately address the complex task of teaching is impossible with the current low quality of students being admitted to schools of education [40]. The first step in addressing the calls for a morally competent practice of special education requires gathering knowledge about the current level of education teacher's moral reasoning from both an ethic of justice and care [41].

The purpose of this study is three-fold. The first purpose is to provide an initial assessment of the current moral reasoning levels of several intact groups of special education teachers. The second purpose is to compare this level of functioning with other groups. The third purpose is to examine some of the characteristics that may be associated with special education teachers level of moral reasoning. Each of these purposes will establish a basic foundation of knowledge and ideas concerning the moral reasoning ability of special education teachers that can serve to further the efforts of the current group of moral reasoning researchers in addressing the moral basis of teaching. These three purposes will be evaluated through four hypothesis. The hypothesis are: 1) Special education teachers will have a higher mean level of moral reasoning, as measured by the Defining Issues Test, than the norm established for adults in general (P Score $40.0)$; 2) Special education teachers will have a higher mean level of moral reasoning, as measured by the Defining Issues Test, than the most recent reported score for teachers in general (P Score 39.5); 3) Special education teachers with more years of experience in education will have higher levels of moral reasoning, as measured by the DIT P-Score, than special education teachers with less years of experience in education; and 4) Teachers who report that they have taken philosophy and/or ethics classes in their undergraduate or graduate preparation will have higher levels of moral reasoning as measured by the Defining Issues Test, than teacher who indicate that they have taken no ethics or philosophy courses.

\section{INSTRUMENT}

The DIT is recognized as the premier instrument for measuring moral reasoning [25]. It has virtually replaced Kohlberg's own moral interview technique, as it offers a more consistent format, immune to the problems frequently encountered in interpreting Kohlberg's original instruments. The Ninth Yearbook of Mental Measurement called the Defining Issues Test (DIT) a "rare example of test construction at its best" [42] (p. 439). The test-retest and internal consistency reliability for the $\mathrm{P}$ scores are reported by the author in the low .80's [28]. The particular advantages of the DIT are ease of administration, a normative base, its objective scoring, standardization, and minimal dependence on verbal expressiveness [22].

The DIT asks the participant to review six hypothetical stories, each of which offers a situation demanding a moral decision. After reviewing each story the participant is asked to respond to a question concerning the appropriate or preferred actions to be taken by the main character in the story. Each issue is then ranked in importance by the participant. The Principled Moral Reasoning score indicates how often the participant indicates that the appropriate action is the action which reflects reasoning at least Stage 5 of Kohlberg's levels of moral reasoning.

Two validity checks are built into the DIT. A Meaningless item score, M-Score, is calculated in the computer scoring process. Meaningless items (items which sound important, but are useless) are included in the possible responses to provide an additional assurance in protecting against irrelevant test taking practices. A significant $\mathrm{M}$-Score indicates that the text taker chose a number of these meaningless responses, which results in the protocol being eliminated from the study. A consistency check compares the relative importance assigned to each of the considerations offered in the test scenarios. An inconsistent pattern of reasoning between scenarios will also result in the protocol being eliminated from the study.

The rapid growth of interest in the field of moral reasoning is evident in the use of the DIT. It has been used in over 1,000 research studies, with "hundreds of thousands" of subjects from the late 1970 s to the present and it has been used in 40 countries, with new studies taking place at the rate of approximately 150 per year [28]. A majority of moral reasoning theorists support that the construct of moral reasoning and stages of moral reasoning are cross-cultural as evidenced by the broad international use of the Defining Issues Test [43]. 
These studies most frequently use the Principled Score (P Score), which indicates the percentage of decisions reflected by the test takers answers that correspond to reasoning at level 5 or level 6 of Kohlberg's stages of moral reasoning. The normative samples established through the extensive broad-based application of the DIT over the last two decades has provided a set of standards that many professions have used to investigate the relative moral reasoning ability of their practitioners.

Chang [25] reported that over the past two decades the Defining Issues Test has contributed greatly to understanding teachers' ability to engage in moral reasoning. She noted that research using the DIT has demonstrated that "the developmental level of moral judgments of preservice and inservice teachers is not satisfactory (p. 72)".

\section{METHOD}

The population for this study will be special education teachers who teach in public schools. A representative sample of special education teachers will be sought from special education teachers working in urban, suburban and rural school districts in a Midwestern state. The superintendent and/or special education administrator will be asked to identify the special education teacher sample in their particular school district. The criteria for inclusion in this sample is that the individuals current teaching position includes the "primary task" of instructing students identified as needing special education. For the purposes of this study, the concept "primary task" will refer to teachers who are identified by the superintendent and/or by the special education administrator as working specifically with children, identified as having disabilities, for a majority of their teaching day.

The sample will include teachers whose "primary task" is serving students in grades $\mathrm{K}$ through 12 , identified as having a disability in the areas of behavior disorders, learning disabilities, developmentally disabilities, cognitively impaired, visually impaired, hearing impaired, multiple disabilities and/or non-categorical special education. Teachers whose "primary task" is to serve students with the above listed disabilities in separate, resource room, regular class and/or noncategorical classrooms will be included in the sample. All of the special education teachers whose primary task is working with children with disabilities in the participating school districts will have an equal opportunity to participate in the sample. This sampling technique will insure that the special education teachers will have the opportunity to participate in the sample at a rate that reflects the current population of special education teachers in the participating school districts. The primary researcher will administer the DIT to at least 250 teachers. Consent will be obtained via verbal agreement.

\section{PROCEDURE}

By prior arrangement with administrators, a testing schedule was established in each of the participating school systems. The schedule offered special education teachers the opportunity to participate in the study in a group or individual format. All teachers, who indicate to the superintendent and/or special educational administrator and/or researcher that they are willing to participate in the sample, and who meet the criteria to be included in the sample, will be pro- vided with at least two opportunities to participate. These schedules may differ from school district to school district, for example, some superintendents and administrators have indicated that they would prefer to offer their teachers the opportunity to complete the demographic questionnaire and DIT test protocol at a previously scheduled meeting. If a teacher chooses to participate, but fails to attend the meeting or would like to complete the instrument in another setting, the researcher will insure that the teacher has at least one alternative opportunity to do so.

A script will be provided to the participating districts and reviewed with each teacher/group of teachers taking the DIT. This procedure was adopted specifically to create uniformity and facilitate replication of this research. The script will include the basic recommendations for test taking practices supplied by the author of the DIT, and it will address each of the concerns of the human subjects review committee. For example, each teacher will be informed via the script-ofinstructions that participation in all, or part, of this study is completely (a) voluntary, (b) anonymous and (c) confidential; and that they can choose to end participation in the inquiry at any point and/or choose not to answer any question at any point.

The demographic information sheet will be numerically coded to match the DIT test protocol. The demographic information sheet will solicit from the special education teachers the following information: (a) years of experience overall in education, (b) age, and (c) disability area(s) served. The approximate time for completing the demographic survey will be about one minute. The DIT can be completed in approximately 45 minutes.

\section{STATISTICAL ANALYSIS PROCEDURES}

Following the administration of the test, the protocols will be sent to the University of Minnesota Center for the Study of Ethical Development for computerized scoring. This scoring procedure employs a computer to scan and quantify the multiple-choice test protocols. This procedure will yield an individual DIT P-Score for each protocol, which will become the dependent variable for each of the statistical procedures, and indicate through the use of two other scales the validity of the test taking practices employed by the sample participant. Protocols deemed unusable will be eliminated at this point, and reported in the results section of this inquiry. The sampling procedures will include an over sampling rate of approximately $100 \%$ to insure that sample mortality will not adversely effect the findings of this study.

\section{DEMOGRAPHICS}

A total of 475 Defining Issues Tests, instruction booklets, demographic information sheets and a note concerning the purpose of this research were supplied to special education coordinators, superintendents, and/or principals with directions to distribute the materials to special education teachers. A total of 355 completed Defining Issues Test protocols were returned from eight counties in a Midwestern state. Fifty-one protocols were judged unusable because of information indicated on the demographic sheet (i.e., not currently teaching special education students, incomplete information, working as a speech pathologist or school psychologist). Elimination of the protocol, as a result of infor- 
mation or lack of information provided on the demographic sheet, is not reflected in the $10 \%$ elimination guideline provided by Rest [22].

A total of 304 Defining Issues Tests were sent to the University of Minnesota Center for the Study of Ethical Development for computerized scoring. Three tests were judged unsuitable for the computer scoring process because of torn or folded pages. The remaining 301 Defining Issues Tests were scored. The computer scoring process indicated that 32 (10\%) of the Defining Issues Tests violated established internal consistency guidelines as indicated by the M Score and the Consistency Check Score. These violations were (a) contained inconsistencies in two or more stories, (b) were not discriminating enough between items within a story, (c) contained excessive errors in a single story, or (d) contained responses reflecting that meaningless items were indicated as important by the test taker.

Table 1. Special Education Teaching Experience

\begin{tabular}{|c|c|}
\hline Years $^{\mathbf{1}}$ & $\mathbf{n}$ \\
\hline \hline 1 & 20 \\
\hline 2 & 21 \\
\hline 3 & 22 \\
\hline 4 & 17 \\
\hline 5 & 18 \\
\hline $6-9$ & 31 \\
\hline $10-13$ & 41 \\
\hline $14-17$ & 47 \\
\hline $18-21$ & 32 \\
\hline $22-26$ & 15 \\
\hline $27+$ & 5 \\
\hline
\end{tabular}

Table 2. Age Category

\begin{tabular}{|c|c|c|}
\hline Age Category $^{2}$ & $\mathbf{n}$ & Percentage $^{\mathbf{2}}$ \\
\hline \hline $20-29$ & 78 & 29 \\
\hline $30-39$ & 82 & 30 \\
\hline $40-49$ & 68 & 25 \\
\hline $50-59$ & 35 & 13 \\
\hline $60-69+$ & 6 & 2 \\
\hline
\end{tabular}

${ }^{1}$ Mean 10.39

Mode 3.00

Median 10.00

Std. Dev. 7.16

${ }^{2}$ Mean 32.9

Mode 30.0

Median 30.0

Std. Dev. 10.9
The inconsistent protocols were eliminated from the sample, leaving 269 Defining Issues Tests for statistical analysis. Rest [22] recommends eliminating tests that exceed the Consistency Check or M-Score established acceptability levels, reporting that this process yields the strongest trends in data by eliminating less reliable data from the sample. He writes that "it is usual in studies to lose between 5 and $15 \%$ of a sample to invalidating from the Consistency Check or M score (p. 15)".

The mean years of experience in special education for the sample were 10.4 years (see Table 1). The mean years not spent as a special education teacher following the first year as a special education teacher was .26 years. The age demographic was collected as a categorical variable (i.e., 20-29, 30-39 years of age) (see Table 2). Scaling the age variable yielded a mean age of approximately 33 years of age for the sample.

\section{RESULTS}

Special education teachers will have a higher mean level of moral reasoning, as measured by the Defining Issues Test, than the most recent reported score for adults in general $(\mathrm{P}$ Score 40.0) and teachers in general (P Score 39.5). The mean P Score for the sample of special education teachers of 35.25 was significantly lower than the most recent reported DIT PScore for a sample of adults in general $40.0(\mathrm{t}-6.10,<.0001)$ and regular education teachers of $39.5(\mathrm{t}-5.45,<.0001)$ (see Table 3). The standard deviation of the DIT P-Score for the special education sample of 12.8 reflects that this sample of special education teachers was notably more homogenous than the most recent study of adults in general [22] and regular education teachers [7].

Special education teachers with more years of experience in special education will have higher levels of moral reasoning, as measured by the DIT P-Score, than special education teachers with less years of experience in special education. Years of experience in special education was not a significant factor in the P-Score for the special education teacher sample ( F 1, 262 p. .08) (see Table 4). With the covariant of Age removed, the special education experience variable remained a non-significant factor in the P-Score for special education teachers ( F 1, 266 p. .20).

Teachers who report that they have taken philosophy and/or ethics classes in their undergraduate or graduate preparation will have higher levels of moral reasoning as measured by the Defining Issues Test, than teachers who indicate that they have taken no ethics or philosophy courses. The number of Philosophy/Ethics Courses variable was a significant factor in the DIT P-Score for the special education teacher sample (F 1, 266 p. .0002) (see Table 5). The mean DIT P-Score for the special education teachers in the sample indicating that they had taken a philosophy/ethics course(s) was 38.12; the mean DIT P-Score for the special education teacher sample indicating that they had not taken a philosophy/ethics course was 32.48.

\section{DISCUSSION}

This is the first study to examine the moral reasoning ability of special education teachers. The primary finding of this research is that special education teachers have a significantly lower level of moral reasoning than the norms estab- 
Table 3. T - Test Results for Hypothesis One and Two

\begin{tabular}{|c|c|c|c|}
\hline & \multicolumn{3}{|c|}{ Defining Issues Test P - Score } \\
\hline Sample & M & SD & t \\
\hline \hline Hypothesis One & & 12.8 & $-6.10^{*}$ \\
\hline Special Education Teacher Sample $(\mathrm{n}=269)$ & 35.25 & 16.7 & \\
\hline Aggregate Adult Norm ${ }^{3}(\mathrm{n}=1149)$ & 40.0 & & $-5.45^{*}$ \\
\hline Hypothesis Two & & 35.25 & 19.5 \\
\hline Special Education Teacher Sample $(\mathrm{n}=269)$ & 39.5 & & \\
\hline General Education Teacher Sample $(\mathrm{n}=24)$ & & & \\
\hline
\end{tabular}

*p $<.0001$

lished for all other reported occupations [28] (see Table 6). While this finding is stark, it is consistent with the literature base in this area. The results were consistent with previous findings reporting that (a) teachers in general have lower levels of moral reasoning ability as measured by the DIT PScore of the Defining Issues Test than other occupations.

Table 4. ANCOVA Results for Hypothesis Three and Four

\begin{tabular}{|c|c|}
\hline \multicolumn{2}{|c|}{ Special Education Teacher Sample (=269) } \\
\hline Variable & F \\
\hline \hline Years in Special Education & 1.2 \\
\hline Years in Special Education * Age & 1.4 \\
\hline Ethics/Philosophy Courses & $12.7 *$ \\
\hline
\end{tabular}

$* \mathrm{p}<.001$

Table 5. Number of Ethics/Philosophy Courses

\begin{tabular}{|c|c|c|}
\hline Courses $^{\mathbf{5}}$ & $\mathbf{n}$ & Percentage \\
\hline \hline 0 & 137 & 51 \\
\hline 1 & 70 & 26 \\
\hline 2 & 29 & 10 \\
\hline 3 & 14 & 5 \\
\hline 4 & 13 & 4 \\
\hline 5 & 6 & 2 \\
\hline $6+$ & 0 & 0 \\
\hline
\end{tabular}

${ }^{3}$ Aggregate set of adults from previous research studies, not a random set of adults selected from the general population. Compiled and reported by Rest [22].

${ }^{4}[7]$

${ }^{5}$ Mean 0.95

Mode 0.00

Median 0.00

Std. Dev. 1.31
Table 6. Different Groups on the DIT P Score ${ }^{6}$

\begin{tabular}{|c|c|}
\hline P - Score & Group \\
\hline \hline 65.2 & Moral Philosophy Grad. Students \\
\hline 59.8 & Liberal Protestant Seminarians \\
\hline 52.2 & Law Students \\
\hline 50.2 & Medical Students \\
\hline 49.2 & Practicing Physicians \\
\hline 47.6 & Dental Students \\
\hline 46.3 & Staff Nurses \\
\hline 42.8 & Graduate Students in Business \\
\hline 42.3 & College Students in General $^{\text {Adults in General }}$ \\
\hline 40.0 & General Education Teachers \\
\hline 39.5 & Special Education Teachers $^{9}$ \\
\hline 35.25 & Senior High School Students \\
\hline 31.8 & Prison Inmates \\
\hline 23.5 & Junior High School Students \\
\hline 21.9 & Institutionalized Deliquents $^{7}$ \\
\hline 18.9 & \\
\hline
\end{tabular}

The finding that the moral reasoning level of special education teachers is significantly below adults in general and significantly below the reported mean level of moral reasoning established for at least 10 other professions has many implications to those charged with preparing special education teachers. When examining the position forwarded in the educational literature that there is a considerable moral mission undertaken by the special educator, it appears that colleges of education have failed to insure that special educators possess the requisite moral reasoning ability to function as a moral agent.

\footnotetext{
${ }^{6}$ Rest [28]

7 Aggregate set of adults from previous research studies, not a random set of adults selected from the general population. Compiled and reported by Rest [22]

${ }^{8}$ [7]

${ }^{9}$ The current sample $(\mathrm{n}=269)$
} 
The findings in Hypothesis One and Two are particularly troubling when viewed in conjunction with current moral reasoning literature on pre-service and in-service teachers in general. A recommendation for pre-service special education programs is to require their majors to pass an ethics course in addition to passing their courses for initial licensure.

McNeel [44] reported that the moral reasoning level of senior education majors was more like freshmen in other college majors than their fellow classmates. He reported "that there may be a moral development problem nationally in the areas of business and education (p. 34)". The findings reported here indicate that if we have a national moral development problem in education and business, we have a particularly severe problem in the field of special education.

Those charged with preparing special educators, may benefit from the established research agenda in other disciplines, possibly enabling them to close the moral reasoning gap illustrated here. There are over one hundred research studies forwarding recommendations and characteristics of educational/vocational interventions that have been demonstrated to be effective in raising the moral reasoning ability of pre-service and inservice practitioners in many vocational and educational settings [44-47]. These recommendations include a wide spectrum of moral enhancement ideas and recommendations, from screening and assessment options, to brief interventions, to program strands, to undergraduate and graduate curriculum options. This body of interdisciplinary research could provide a valuable resource for constructing special education teacher preparation programs that include addressing the moral/ethical aspects of teacher preparation.

This research has established a foundation of knowledge concerning the moral reasoning ability of special education teachers. The establishment of a foundation of knowledge concerning the moral reasoning ability of practitioners was the key to subsequent research and development in the area of moral reasoning in other professions. A profession conspicuous in its absence from this moral/ethical evolution has been special education.

This study poses a number of questions that can be applied to a host of diverse educational debates and dialogues. For example, is there a relationship between the low moral reasoning level of special educators found in this study and (a) the professionalization of teaching and/or special education, (b) building collaborative relationships, (c) attitudes towards inclusive educational programming, (d) attitudes towards individuals with disabilities, (e) teacher supply and demand issues, and/or (f) admission and screening of potential special education majors' dispositions?

\section{REFERENCES}

[1] Fenstermacher GD. Some moral considerations on teaching as a profession. In: Goodlad Jl, Soder R, Sirotnik KA, Eds. The moral dimensions of Teaching. San Francisco, CA: Jossey-Bass 1990; pp. 130-55.

[2] Rest J. Does moral education improve moral judgment? A metaanalysis of intervention studies using the defining issue test. Rev Educ Res 1985; 55: 319-52.

[3] Bebeau MJ. Designing an outcome-based ethics curriculum for Professional education: Strategies and evidence of effectiveness. J Moral Educ 1993; 22: 313-25.

[4] Beyer L. Schooling, moral commitment, and the preparation of teachers. J Teacher Educ 1991; 42(3): 205-15.
[5] Husu J, Tirri K. A case study approach to study one teacher's moral reflection. Teach Teach Educ 2002; 19: 345-57.

[6] Joseph PB, Efron S. Moral choices/moral conflicts: Teachers' selfperceptions. J Moral Educ 1993; 22: 201-21.

[7] MacCallum JA. Teacher reasoning and moral judgment in the context of student discipline situations. J Moral Educ 1993; 22: 3-17.

[8] Maslovaty N. Teachers' choice of teaching strategies for dealing with socio-moral dilemmas in the elementary school. J Moral Educ 2000; 29: 429-44.

[9] Noddings N. Conversations as moral education. J Moral Educ 1994; 23: 107-19.

[10] Oser FK. Morality in professional action: A discourse approach for teaching. In: Oser F, Dick A, Patry JL, Eds. Effective and responsible teaching: The new synthesis. San Francisco: Jossey Bass 1992; pp. 109-25.

[11] Palmer B. Morals education: A teacher education perspective. School of Educ Rev 1991; 3: 13-6.

[12] Pekarsky D. Socratic teaching: A critical assessment. J Moral Educ 1994; 23: 119-35.

[13] Reiman AJ, Peace SD. Promoting teacher's moral reasoning and collaborative inquiry performance: A developmental role-taking and guided inquiry study. J Moral Educ 2002; 31(1): 51-66.

[14] Rogers D, Webb J. The ethic of caring in teacher education. J Teacher Educ 1991; 42: 173-81.

[15] Skoe EE, Diessner R. Ethic of care, justice, identity, and gender: An extension and replication. Merrill Palmer Quart 1994; 40: $272-$ 89.

[16] Althof A, Oser F. Professional morality: Ethical dimensions of teaching. J Moral Educ 1993; 22: 197-200.

[17] Sockett H. Accountability, trust and ethical codes of practice. In: Goodlad JL, Soder R, Sirotnik KA, Eds. The moral dimension of teaching. San Francisco: Jossey Bass 1990.

[18] Goodlad J. The occupation of teaching in schools. In: Goodlad J1, Soder R, Sirotnik KA. Eds. The moral dimensions of teaching San Francisco: Jossey-Bass 1990; pp. 3-34.

[19] Strike KA, Soltis JF. The ethics of teaching. 2nd ed. New York: Teachers College Press 1992.

[20] Bergem T. The teacher as moral agent. J Moral Educ 1990; 19: 88100 .

[21] Gerety MA. A study of the relationship between the moral judgment of the teacher and the moral atmosphere in the classroom. Diss Abstr Int 1980; 41: 1952A.

[22] Rest J. Manual for the defining issues test: An objective test of moral judgment. $3^{\text {rd }}$ ed. Minneapolis: University of Minnesota 1986.

[23] Rybash J. How teachers help children resolve moral dilemmas. J Moral Educ 1980; 10: 18-23.

[24] Wilkins R. If the moral reasoning of teachers is deficient, what hope for pupils? Phi Delta Kappan 1980; 61: 548-9.

[25] Chang FY. School teacher moral reasoning. In: Rest J, Narvaez D, Eds. Moral development in the professions: Psychology and applied ethics. Hillsdale, NJ: Lawrence Erlbaum Associates 1994; 71 84.

[26] Diessner R. Teacher education for democratic classrooms: Moral reasoning and ideology critique. A seminar presented at the 16th Annual Conference of the Association for Moral Education; Athens, GA 1991.

[27] Hilton JB. Teachers' moral reasoning and students' perception of teacher affect. PhD [dissertation]. University of South Carolina: Columbia 1989.

[28] Rest JR. Background: Theory and research. In: Rest J, Narvaez D, Eds. Moral development in the professions: Psychology and applied ethics. Hillsdale, NJ: Lawrence Erlbaum Associates 1994; pp. $1-26$.

[29] Fullan M. Change forces: Probing the depths of education reform. London: Falmer 1993.

[30] Goodlad J, Soder R, Sirotnik K. Eds. The moral dimensions of teaching. San Francisco: Jossey-Bass 1990.

[31] Reiman AJ. A comparison of four-year longitudinal studies of postconventional moral judgment reasoning in teacher education and other selected undergraduate samples. Annual Meeting of the American Educational Research Association; New Orleans, LA; Available from: ERIC Document Reproduction Services 2002.

[32] Blotner R, Bearison DJ. Developmental consistencies in sociomoral knowledge: Justice reasoning and altruistic behavior. Merrill Palmer Q 1984; 30: 349-67. 
[33] Eisenberg N. Altruistic emotion, cognition, and behavior. Hillsdale, NJ: Erlbaum 1986.

[34] Houston JP. Kohlberg type moral instruction and cheating behavior. Coll Stud J 1983; 17: 196-204.

[35] Schlaefi A, Rest J, Thoma, S. Does moral education improve moral judgment? A meta analysis of intervention studies using the defining issues test. Rev Educ Res 1985; 55: 319-52.

[36] Blasi A. Bridging moral cognition and moral action: A critical review of the literature. Psychol Bull 1980; 88: 593-637.

[37] Duckett LJ, Ryden. Education for ethical nursing practice. In: Rest J, Narvaez D Eds. Moral development in the professions: Psychology and applied ethics. Hillsdale, NJ: Lawrence Erlbaum Associates 1994; pp. 51-70.

[38] Tippins DJ, Tobin KG, Hooks K. Ethical decisions at the heart of teaching: Making sense from a constructivist perspective. J Moral Educ 1993; 22: 221-40.

[39] Lipsky D, Gartner A. Taking inclusion into the future. Educ Leadersh 1998; 56(2): 78-81.

[40] Seldin CA. Professionalizing teaching: Being selective from the start. Kappa Delta Pi Rec 1995; 31(2): 68-72.
[41] Rice CJ. Teachers' level of care. Education 2001; 122(1): 102-6.

[42] Mitchell JV, Ed. The mental measurements yearbook. Lincoln: University of Nebraska 1985.

[43] Snarey JR. Development of social-moral reasoning among kibbutz adolescents: A longitudinal cross-cultural study. Dev Psychol 1985; 21: 3-17.

[44] McNeel SP. College teaching and student moral development. In: Rest J, Narvaez D, Eds. Moral development in the professions: Psychology and applied ethics. Hillsdale, NJ: Lawrence Erlbaum Associates 1994: 27-50.

[45] Baldwin DC, Jr. Daugherty S, Self DJ. Changes in moral reasoning during medical school. Acad Med 1991; 66: 1-3.

[46] Self DJ, Baldwin DC Jr, Olivarez M. Teaching medical ethics to first-year students by using film discussion to develop their moral reasoning. Acad Med 1993; 68: 383-85.

[47] St. Pierre K, Nelson E, Gabbin A. A study of the ethical development of accounting majors in relation to other business and nonbusiness disciplines. Acc Educ J 1990; 2: 23-35.

(C) Rice and Stein; Licensee Bentham Open.

This is an open access article licensed under the terms of the Creative Commons Attribution Non-Commercial License (http://creativecommons.org/licenses/by$\mathrm{nc} / 3.0 /$ ) which permits unrestricted, non-commercial use, distribution and reproduction in any medium, provided the work is properly cited. 